\title{
REPLY TO COMMENTS BY A. DOUGLAS, J. B. YOUNG, AND N. S. LYMAN AND A NOTE ON THE REVISED MOMENTS FOR PAHUTE MESA TECTONIC RELEASE
}

\author{
By T. C. Wallace, D. V. Helmberger, and T. LaY
}

In two earlier papers (Wallace et al., 1983, 1985), we discussed the evidence for tectonic release from underground nuclear explosions on Pahute Mesa at the Nevada Test Site (NTS) as observed in long-period body waves. It has been shown for some time that the nonisotropic component of the surface waves from most of these events could be explained by an equivalent double-couple source; namely strike-slip motion on north-striking faults. In an attempt to get better resolution on the mechanism of the tectonic release, we modeled the $S H$ wave forms using the constraints imposed by reversals in the $S V$ polarity and distortions in the longperiod $P$ waves. We found that the orientation inferred from the body waves closely matched those determined from the surface waves. Further, we were able to determine the seismic moments for the tectonic release by comparison with several shallow, strike-slip earthquakes. Although the $S H$ waveforms provide the most direct measure of the tectonic release, the tectonic release mechanism adequately explains a wide range of long-period body wave observations. In particular, we identified a distortion in the upper mantle long-period $P$ waves which we attribute to the phase $S P$ from the tectonic release. The amplitude of this phase correlates very well with the moment of the tectonic release; it can be modeled by adding a strike-slip synthetic to the waveform of a low tectonic release event (see Figures 6 and 8 in the 1983 paper); and finally it shows a change in polarity (see Figure 9 in the 1983 paper; Figure 5 in the 1985 paper) as expected by the strike-slip radiation pattern. The identification of the $s P$ phase provided the highest frequency signature of tectonic release $(\sim 0.33 \mathrm{~Hz})$ yet known and suggested that short-period $P$ waves could also be affected by tectonic release. With this in mind, Lay et al. (1984) studied the first cycle $(a b)$ amplitude of the teleseismic short-period $P$ waves from the Pahute Mesa events and found a systematic azimuthal variation which is consistent with a distortion which could be caused by the tectonic release.

Douglas et al. (1985) suggest that we have misinterpreted the complexity in the $P$ waves, and actually the distortion is caused by slap down, and that there is no evidence to support that tectonic release is influencing the first $P$ wave arrivals from explosions at NTS. The principal data Douglas cites are the broadband recordings at EKA of the large Pahute Mesa events (Figure 1 in Douglas et al., 1985). If our interpretation of tectonic release is correct, Douglas contends that the deflection he has marked $A_{0}$ should have a negative polarity, which it does not. It is important to note here that these backswings in the $P$ waves are interference patterns between the explosion $P, p P$, and any contribution of slapdown with that of the $s P$ phase is from the tectonic release. Such interference patterns are very sensitive to the relative timing of the different episodes. A small shift in the location of the tectonic release relative to the explosion can produce a "misleading" polarity. (It is also difficult to interpret Figure 1 in Douglas et al. since explosions of much different size are all plotted with a normalized amplitude scale.) A direct comparison between Figure 1 in Douglas et al. and Figure 5 in Wallace et al. shows that, in fact, the backswing in question is greatly reduced relative to direct $P$ for the high tectonic release events such as MUENSTER and BENHAM at EKA which is consistent 
with the tectonic release interpretation. It also must be remembered that SHA (the station Wallace et al. used for comparison) is $24^{\circ}$ from NTS, while EKA is approximately $70^{\circ}$ away. This change in distance corresponds to a change in the surface reflection coefficient of $s P$ from -0.55 to -0.36 ; or a reduction by one-third at EKA as compared to SHA.

We want to reiterate that the reason we favor the interpretation that tectonic release can have a signature on long-period $P$ waves is its consistency with a large data set. The amplitude of the $s P$ phase is consistent with that predicted on the basis of the $S H$ waves. The $S V$ phase from BENHAM and GREELEY shows a phase reversal which is consistent with the orientation determined for the tectonic release double couple. The $S V$ reversal is accompanied by a reversal in polarity of the phase we have identified as $s P$. The long-period regional distance body waves $\left(P_{n l}\right)$ also show a distortion which is consistent with the interference from strikeslip tectonic release. In the case of the $P_{n l}$ waveforms, the signature is over a 45 -sec window rather than a single arrival $(s P)$. Although we have not modeled slapdown, and as Douglas $e t$ al. point out it can have an effect on the long-period $P$ waves, we believe it cannot account for all the observations listed above. In particular, slapdown cannot produce the four-lobed $S H$ radiation pattern, nor the polarity reversal of $s P$. Further, one of the most remarkable facts about the tectonic release from NTS is its consistency in orientation. With only two or three exceptions (HALFBEAK and PILEDRIVER), the tectonic release is dominately strike-slip motion on north-trending planes. It is very difficult to appeal to a form of explosion source anisotropy or slapdown that will always produce an identical apparent double-couple radiation pattern.

The question of whether the tectonic release has a signature at the frequencies of short-period $P$ waves is a separate matter. For the most part, the short-period waveforms are quite complicated, and no one has convincingly identified an equivalent of the long-period $s P$ phase. Lay et al. (1984) simply plotted the corrected $a b$ amplitude of 25 Pahute Mesa explosions versus azimuth and noted that they appeared to have a $\sin (2 \phi)$ variation. Lay et al. found that the best fit of a $\sin (\phi)$ curve to the amplitudes was consistent with the pattern that would be expected from the azimuthal radiation pattern for a vertical strike-slip fault with the orientation given by the analysis of the long-period $S H$ waveforms. The significance of the $\sin (2 \phi)$ fit was evaluated with an $f$-test. Nearly all the Pahute Mesa pass the test at the 99th per cent level, but most importantly, the events with the largest long-period tectonic release show the clearest $\sin (2 \phi)$ pattern. There are alternative explanations for the amplitude behavior, such as upper mantle structure beneath Pahute Mesa (Lynne and Lay, 1984), but again the consistency with all the other tectonic release data suggest that the $a b$ amplitude "could be" modulated by a strikeslip radiation pattern.

Lay et al. also cite differences in waveform between stations near the node and those in the lobe as evidence of tectonic release. Douglas et al. suggest that the change in waveform is due to lateral variations in attenuation. In particular, they map the loop station (UME) into the node station (OGD) by increasing $t^{*}$ by a factor of 2 (see Figure 4 in Douglas et al.). One way to test this path bias hypothesis is to compare UME and OGD for FAULTLESS which was detonated $100 \mathrm{~km}$ north of Pahute Mesa; the waveforms for the two stations are nearly identical (see Lay et $a l$., Figure 11). Further, we can test the stability of the $\sin (2 \phi)$ pattern from the Pahute Mesa events by comparing them to FAULTLESS. Figure 7 in Lay et al. shows that amplitude pattern from FAULTLESS is significantly different than 
that of GREELEY; in fact, they are nearly reversed. If one wants to appeal to attenuation to produce the $\sin (2 \phi)$ pattern, then it must also account for the FAULTLESS pattern. It seems unlikely that slight travel path differences between FAULTLESS and GREELEY to teleseismic distance stations would produce the factor of 5 change in relative amplitude.

Recently, Given and Mellman (1985) have analyzed the surface waves from several of the Pahute events using sophisticated phase velocity and attenuation correction developed for NTS by Stevens et al. (1982). Given and Mellman determined an orientation for the nonisotropic radiation which we have plotted against the strike of $\sin (2 \phi)$ pattern observed by Lay et al. (1984) for a set of eight events

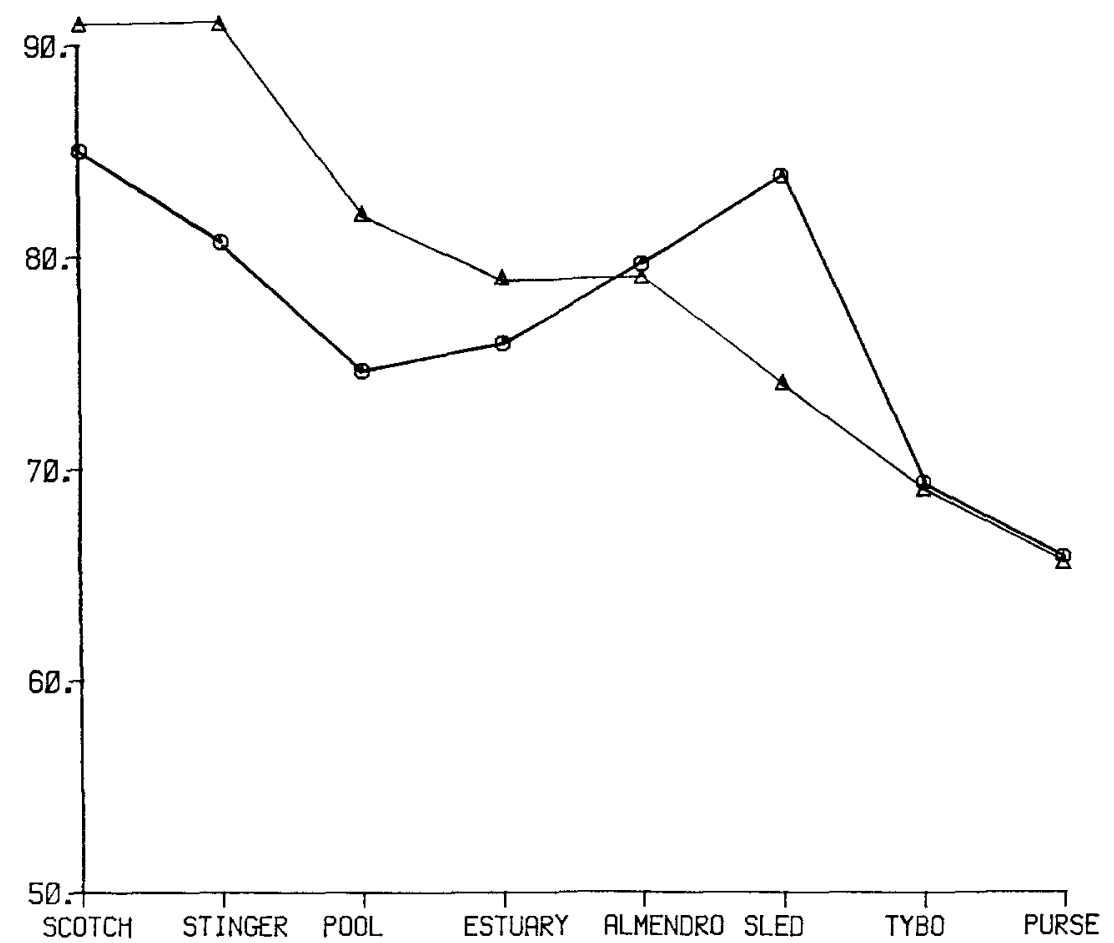

FIG. 1. Strike (in degrees) of the tectonic release double couple as determined from long-period surface waves (triangular symbols) compared to the strike of the $\sin (2 \phi)$ azimuthal variation observed in the $a b$ amplitude of the short-period $P$ waves. All of the events are within Silent Valley Caldera.

in Figure 1. The strike of the double couple varies from $90^{\circ}$ to $65^{\circ}$ for the different events. Although there is some difference in the absolute value of the strikes as determined by the surface and body waves, their agreement is good. More remarkable is the fact that as the strike varies, the short-periods track the long-periods very well. It should be noted that this correlation breaks down for events outside or near the edge of Silent Valley Caldera. Again, the point of the figure is that the shortperiod $P$ wave amplitudes correlate with the long-period tectonic release. Neither structure or attenuation can be ruled out as causing the short-period pattern, but there is no reason that the short-period $P$ waves should correlate with long-period Love and Rayleigh waves unless tectonic release is causing the modulation.

One difficulty with our 1985 paper is the large moments we determined for the tectonic release. These values were determined on the basis of comparison of $\mathrm{SH}$ waves from two earthquakes: (1) 16 August 1966, near the Nevada-Utah border, 
and (2) 15 March 1979, in Homestead Valley in south central California. The moment values were very consistent from station to station when compared to either earthquake. Unfortunately, the average values for a given explosion varied by a factor of 2 depending on the reference earthquake. The 16 August 1966 earthquake consistently gave moments which were twice those determined using the 15 March 1979 event. Since we did not know which estimate was more reliable,

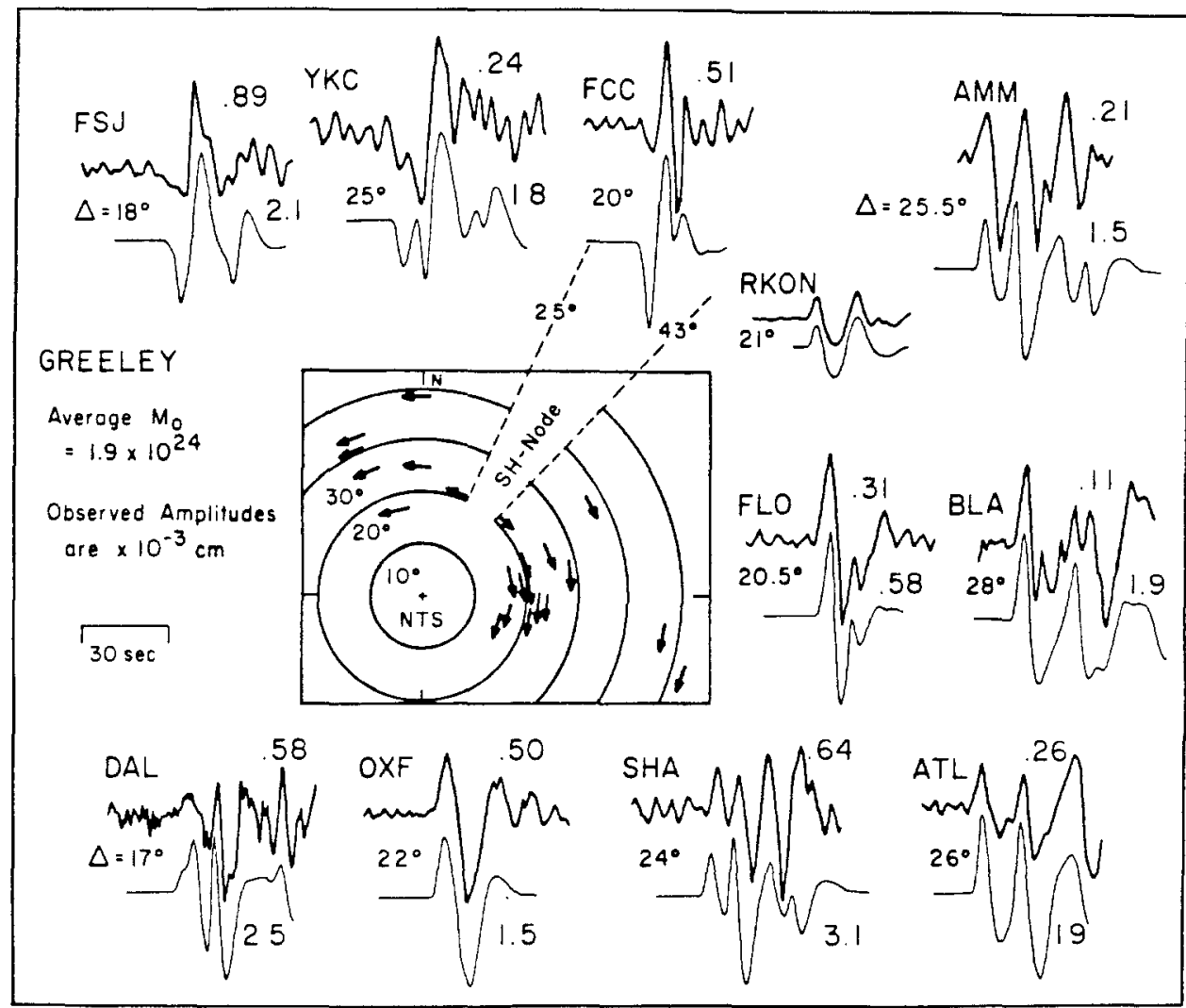

FIG. 2. A comparison of the $S H$ waveforms from the explosion GREELEY with synthetics generated for a vertical strike-slip fault with the orientation consistent with Pahute Mesa tectonic release. The structure model used is laterally varying (see Helmberger et al., 1985). Above the observed $S H$ pulse is the maximum amplitude in $10^{-3} \mathrm{~cm}$, while the number below the synthetic is the moment required to produce the observed amplitude.

we averaged the values to produce Table I in the 1985 paper. Since that publication, several investigators have shown that there is a strong velocity variation across the Rocky Mountain front (Grand and Helmberger, 1984). Since the 16 August 1966 earthquake is along the front, it is probably inappropriate to use it as a calibration for NTS. Helmberger et al. (1985) have developed a lateral varying model for the North American continent. We used this model to construct synthetic seismograms for a strike-slip orientation and compare them to GREELEY in Figure 2. As can be seen, the waveform fit is quite good; the average moment we obtain is $1.9 \times 10^{24}$ dyne-cm which is in very close agreement with value we determine for GREELEY by the comparison with the 15 March 1979 earthquake. On the basis of this, we 
have revised the moments for tectonic release for 21 Pahute Mesa events. The new values are given in Table 1.

Since our revised moments are smaller, the potential for tectonic release to influence the short-period $P$ waves is also reduced. Although we are confident that tectonic release can have an identifiable signature on long-period $P$ waves (2 to 5 sec), it has not conclusively been shown that it influences short-period $P$ waves. The only way to address the question of $m_{b}$ bias is to analyze large data sets, and attempt to model complexity such as Douglas et al.'s slapdown phase.

TABLE 1

Revised Moments for Tectonic Release from Pahute Mesa Explosions

\begin{tabular}{lccccccc}
\hline \multicolumn{1}{c}{ Name } & $\begin{array}{c}\text { Date } \\
(\mathrm{m}-\mathrm{d}-\mathrm{yr})\end{array}$ & $\begin{array}{c}\text { Origin } \\
\text { Time }\end{array}$ & $\begin{array}{c}\text { Latitude } \\
\left({ }^{\circ} \mathrm{N}\right)\end{array}$ & $\begin{array}{c}\text { Longitude } \\
\left({ }^{\circ} \mathrm{W}\right)\end{array}$ & $\begin{array}{c}\text { Depth } \\
(\mathrm{km})\end{array}$ & $m_{b}$ & $M_{\mathbf{0}} \times 10^{24}$ \\
\hline Almendro & $06-06-73$ & $13: 00$ & 37.24 & 116.35 & 1.064 & 6.1 & 0.61 \\
Benham & $12-19-66$ & $16: 30$ & 37.23 & 116.47 & 1.402 & 6.3 & 3.43 \\
Boxcar & $04-26-68$ & $15: 00$ & 37.29 & 116.46 & 1.158 & 6.2 & 0.86 \\
Camembert & $06-26-75$ & $12: 30$ & 37.28 & 116.37 & 1.311 & 6.1 & 0.86 \\
Cheshire & $02-14-76$ & $11: 30$ & 37.24 & 116.47 & 1.167 & 5.8 & 0.43 \\
Colby & $03-14-75$ & $12: 30$ & 37.31 & 116.47 & 1.273 & 6.2 & 0.49 \\
Estuary & $03-09-76$ & $14: 00$ & 37.31 & 116.36 & 0.869 & 5.8 & 0.43 \\
Fontina & $02-12-76$ & $14: 45$ & 37.27 & 116.49 & 1.219 & 6.1 & 1.35 \\
Greeley & $12-20-66$ & $15: 30$ & 37.30 & 116.41 & 1.215 & 6.3 & 1.90 \\
Halfbeak & $06-30-66$ & $22: 15$ & 37.32 & 116.30 & 0.819 & 6.1 & 0.61 \\
Handley & $03-26-70$ & $19: 00$ & 37.30 & 116.53 & 1.206 & 6.4 & 1.47 \\
Inlet & $11-20-75$ & $15: 00$ & 37.22 & 116.37 & 0.817 & 5.9 & 0.18 \\
Jorum & $09-16-69$ & $14: 30$ & 37.31 & 116.46 & 1.158 & 6.1 & 0.31 \\
Kusseri & $10-28-75$ & $14: 30$ & 37.29 & 116.41 & 1.265 & 6.2 & 1.22 \\
Mast & $06-19-75$ & $13: 00$ & 37.35 & 116.32 & 0.912 & 5.9 & 0.31 \\
Muenster & $01-03-76$ & $19: 15$ & 37.30 & 116.33 & 1.451 & 6.2 & 1.96 \\
Pipkin & $10-08-69$ & $14: 30$ & 37.26 & 116.44 & 0.617 & 5.6 & 0.12 \\
Pool & $03-17-76$ & $14: 15$ & 37.26 & 116.31 & 0.879 & 6.0 & 0.12 \\
Scotch & $05-23-67$ & $14: 00$ & 37.27 & 116.37 & 0.978 & 5.7 & 0.18 \\
Stilton & $06-03-75$ & $14: 20$ & 37.34 & 116.52 & 0.731 & 5.8 & 0.07 \\
Tybo & $\mathbf{0 5 - 1 4 - 7 5}$ & $14: 00$ & 37.22 & 116.47 & 0.765 & 5.9 & 0.18 \\
\hline
\end{tabular}

\section{REFERENCES}

Douglas, A., J. B. Young, and N. S. Layman (1985). Spalling and tectonic release associated with underground explosions at the Nevada Test Site: evidence from broad band $P$ waves, Bull. Seism. Soc. Am. 76, 305-311.

Given, J. W. and G. R. Mellman (1985). Source parameters for nuclear explosions at NTS and Shagan River from observations of Rayleigh and Love waves, presented at the DARPA/AFGL Seismic Research Symposium, May 6-8, 1985.

Grand, S. P. and D. V. Helmberger (1984). Upper mantle shear structure of North America, Geophys. J. R. Astr. Soc. 76, 399-438.

Helmberger, D. V., G. R. Engen, and S. P. Grand (1985). Upper mantle cross section from California to Greenland, Geophys. J. (in press).

Lay, T., T. C. Wallace, and D. V. Helmberger (1984). The effects of tectonic release on short-period $P$ waves from NTS explosions, Bull. Seism. Soc. Am. 74, 819-842.

Lynne, C. and T. Lay (1984). Defocussing of short period $P$ waves by a high velocity anomaly beneath Pahute Mesa, EOS, Trans. Am. Geophys. Union 65, 994.

Stevens, J. L., W. L. Rodi, J. Wang, B. Shkoller, E. J. Halda, B. F. Mason, and J. B. Minster (1982). Surface wave analysis package and Shagan River to SRO station path corrections, S-Cubed Topical Report VSC-TR-82-81.

Wallace, T. C., D. V. Helmberger, and G. K. Engen (1983). Evidence of tectonic release from underground nuclear explosions in long-period $P$-waves, Bull. Seism. Soc. Am. 73, 593-613. 
Wallace, T. C., D. V. Helmberger, and G. K. Engen (1985). Evidence of tectonic release from underground nuclear explosions in long-period $S$ waves, Bull. Seism. Soc. Am. 85, 157-174.

DePARTMENT OF GeOSCIENCES

UNIVERSITY OF ARIZONA

Tucson, ARIZONa 85721 (T.W.)

SEISMOLOGICAL LABORATORY

California Institute of Technology

Pasadena, California 91103 (D.V.H.)
DEPARTMENT OF GEOLOGICAL SCIENCES

UNIVERSITY OF MICHIGAN

1006 C. C. Little Building

ANN ARBoR, MrCHIGAN 48109 (T.L.)

Manuscript received 31 July 1985 